\title{
Social Adaptation and Its Relationship to Achievement Motivation among High School Students in Jordan
}

\author{
Saleem Odeh AlZboon ${ }^{1}$ \\ ${ }^{1}$ The World Islamic Sciences \& Education, Faculty of Arts And Educational Sciences, Jordan \\ Correspondence: Saleem Odeh AlZboon, Associate Professor, The World Islamic Sciences \& Education, Faculty \\ of Arts And Educational Sciences, Jordan. Tel: 962-777-467-861. E-mail: drzboon@yahoo.com
}

\author{
Received: July 8, 2013 Accepted: August 5, 2013 Online Published: September 26, 2013 \\ doi:10.5539/ies.v6n10p63 URL: http://dx.doi.org/10.5539/ies.v6n10p63
}

\begin{abstract}
The study amid at exploring and detecting the level of social adaptation and its relationship with the achievement motivation of the secondary school students in Jordan, the study sample consisted of 495 secondary school students in the province of Jerash, and to achieve the objective of this study comes the development of two tools: the first one measures the social adaptation, and the second one measures the achievement motivation.

The study found many results, including: that the level of social adaptation and achievement motivation among secondary school students in the province of Jerash were high, and also showed the presence of a statistically significant positive relationship between the social adaptation and the achievement motivation among the secondary school students in the province of Jerash too; therefore and in light of these results, the researcher recommends conducting further studies exploring the social adaptation relationship to other variables.
\end{abstract}

Keywords: social adaptation, achievement motivation

\section{Introduction}

social adaptation is considered one of the important issues directly linked to human behavior, which is in turn a reaction of an individual trying to achieve harmonization of his motives and needs on one hand, and the requirements of the environment and the different circumstances in the other hand; so he cares about the positive actions that brings satisfaction and leads to more social acceptance, and therefore the ability to adapt in different life situations.

The adaptation process occurs as an interaction between the individual and the surrounding environment in order to satisfy his motives and incentives, which must include a changing process in behavior to fit the surrounding environment changes, and also must include the feedback behavioral and psychological responses that can adjust his behavior for responding to these changes (Ahmad, 1996).

The purpose of life is to adapt with the environment, and to succeed in dealing with others so as to achieve personal adaptation, convenience, and self fulfillment; where humans since birth learn how to adapt with different circumstances, conditions and attitudes to know how to interact with others and to meet their own needs, and then to achieve satisfaction; which requires a deep knowledge of these needs by exploring the potential of the adaptation processes with the environment and the best practices of handling others (Mousa and El-Desoki, 2000).

\section{Literature and Related Studies}

The adaptive individual reaches the phase were his behaviors and actions correspond with the social environment in which he lives, then he will achieve a positive balance in his social relations with the social milieu around him, positively affecting all his various life aspects (Anani, 2000).

Thereby, social adaptation refers to the individual alignment between his reality, thoughts and the internal culture with his environmental socio-cultural concepts that may be arising from the ideological and the intellectual differences between him and his society, and then he tries to adapt so as to achieve that kind of balance between him and the surrounding environment, in which he can meet his needs by developing positive relationships based on vulnerability and mutual influence, which is the main objective of congenital growth processes of the individual at his different stages of life (Abdullah, 2001). 
It is clear that the individual's social adaptation leads to the balance in his relationship with his environment, peers and his school, which of course will increase his achievement motivation, and will help him exploiting his energies and abilities to the possible fullest extent. Mayahi (2010) sees that the achievement motive is the most important and directly affected by the proper adaptation with the social environment.

Achievement motivation is one of the acquired motivations that sparked a lot of debate and controversy among educators, and it is one of the inherent needs which are associated with the motivated plaudits of the individual. Murray is one of the first experts of education and psychology interested in this concept, whom to which credited introducing the concept of the achievement need to the psychological heritage, and presenting it as an important component of personal (Gobari, 2008).

Achievement motivation during the years of the study is also considered one of the important motives in guiding the student's behavior towards accepting the challenge in situations that require excellence, and to make serious attempts to achieve success (Mayahi, 2010).

In this area (Wilson, 1994) had conducted a study aimed to identify the types of adaptation problems facing students at the University of Zambia, and the results showed that the academic problems which appear in the form of academic loads, finding references scheduled to school articles, and the commitment to one majoring in particular are the most important problems that affect the adaptation of the students in the university. Results also showed that the financial problems appearing in the form of weak sufficient financial resources enough to purchase textbooks, or for the daily expenses are also among the most important problems that affect adaptation.

Taylor (1998), highlighted the close relationship between the academic and the social adaptation of foreign students with many other variables in the United States, the study showed a significant high correlation between the age of the students and their adaptation to life; as younger students are more adaptable than older students, and also showed the presence of a significant high correlation between the financial situation of the students and their adaptation to life; as students with good financial situation are good adapters too and students with poor financial situation are less adapters.

Adeymo, (2005) study had showed a statistically significant correlation between the level of emotional intelligence and the social adaptation among secondary school students, and that the positive social adaptation plays an important role through the transition phase from middle school to high school.

Cerezo \& Casanova, (2004) study had declared that the level of achievement motivation among female students was higher than male students, and this gender differences existence was in the favor of female students especially in the level of external motivation, the level of responsibility for academic failure, and in the ability of processing provided information.

Areepattamanil \& Freeman, (2008) had conducted a study aimed at detecting the academic achievement, the academic self-concept and the achievement motivation among high school students in the Canadian province of Toronto. The results indicated statistically significant differences in the level of academic achievement, academic self-concept, and achievement motivation among high school students from ordinary families and immigrant families, for the benefit of students of immigrant families.

Chex, Wang \& Cao, (2011) had found a correlation between lack of interaction with peers in school and the problems associated with the social adaptation and also the adaptation to school, it also noted the presence of correlation between shyness and negative social adaptation among high school students participating in the study.

Teang, Lau \& Nie, (2011) had conducted a study aimed at detecting the achievement motivation among the students of primary and secondary schools, by trying to detect the gender differences at the educational level, the study had indicated the presence of gender differences in favor of female students in the achievement motivation, and also indicated the existence of differences related to the level of education in favor of younger students. The results of this study indicated that female students in primary grades had received top marks in the scale of achievement motivation.

Students, like other members of society, their motivations and needs will sit their levels of social adaptation depending heavily on their ability to deal with those motives, needs and problems.

Social adaptation and the social sense of any student will affect achievement and attainment; thus forcing educational institutions to help students in order to reach an adequate standard of self adaptation is a must.

The importance of both social adaptation and achievement motivation among secondary school students, and their role in achieving the objectives of Education in the province of Jerash, goes in line with the researcher desire to analyse these relationships. 


\section{Problem of the Study}

The purpose of this study is to detect the level of social adaptation and its relationship to achievement motivation among secondary school students in the province of Jerash.

\section{Questions of the Study}

To achieve the goal of this study these following questions should be answered:

1) What is the level of social adaptation among secondary school students in the province of Jerash?

2) What is the level of achievement motivation among secondary school students in the province of Jerash?

3) Is there a statistically significant correlation at the level of $(\alpha \leq 0.05)$ between the level of social adaptation and achievement motivation among secondary school students in the province of Jerash?

\section{Methods and Procedures}

\subsection{Methodology}

The relational descriptive approach is used in this study, for its relevance to the nature of the current study as appointed to organize the data and to find a correlation between the different variables when accessing the accurate data

\subsection{The Study Population}

The study population included all the current high school students in the province of Jerash secondary schools for the academic year 2012/2013, totaling (4950) students.

\subsection{The Study Sample}

The representative sample was selected from the study population reaching (495) students as a ratio of $10 \%$ of the study population, and distributed at various high schools in the province of Jerash; table 1 shows the distribution of the study sample by gender.

Table 1. Distribution of the study sample by gender

\begin{tabular}{llll}
\hline & Categories & Repetition & Percentages \\
\hline \multirow{3}{*}{ Gender } & males & 289 & $58.4 \%$ \\
& females & 206 & $41.6 \%$ \\
& total & 495 & $100 \%$ \\
\hline
\end{tabular}

\subsection{Study Tools}

To achieve the objectives of the study two tools were prepared as follows:

\subsubsection{Social Adaptation Scale}

To achieve the objectives of the current study and to collect the accurate data of the research, a questionnaire was prepared to detect the levels of social adaptation among secondary school students in the province of Jerash, and to fulfill the measurement in its final form this part of the questionnaire consented of (29) paragraph, then it was conducted to the reliability of the content that is clear in the paragraphs scale association with the objectives prepared for this purpose, and with the extent of acceptance with the framework of the community of the targeted individuals, and of course a group of professional arbitrators were polled.

\subsubsection{The Validity of the Social Adaptation Scale}

To ensure the validity of the tool, the Pearson correlation coefficient was calculated upon exploratory sample from outside the study sample of (20) students of the secondary school students in the province of Jerash, reaching (0.88).

\subsubsection{Achievement Motivation Scale}

To achieve the objectives of the study, and to collect the accurate data on the subject of the research, a questionnaire was prepared to detect the levels of achievement motivation among secondary school students in the province of Jerash, and to fulfill the measurement in its final form, this part of the questionnaire consented of (18) paragraph. 


\subsubsection{Validity of the Achievement Motivation Measurement Tool}

Validity of the content that is clear in the paragraphs scale associated with the objectives, as it was prepared for this purpose, and the extent of acceptance with the framework of the community of the targeted individuals, and of course a group of professional arbitrators were polled too.

\subsubsection{Reliability of the Achievement Motivation Measurement Tool}

To ensure the validity of the tool, the Pearson correlation coefficient was calculated upon exploratory sample from outside the study sample of (20) students of the secondary school students in the province of Jerash, reaching (0.90).

\section{Study Results}

The results of the first question which states: "What is the level of social adaptation among the secondary school students in the province of Jerash?"

To answer this question the arithmetic means and the standard deviations of the level of social adaptation among secondary school students in the province of Jerash have been extracted, and illustrated in table 2 as follows:

Table 2. Arithmetic means and standard deviations of the level of social adaptation among secondary school students in the province of Jerash in descending order according to the arithmetical means

\begin{tabular}{|c|c|c|c|c|c|}
\hline No. & Paragraph & $\begin{array}{l}\text { Arithmetic } \\
\text { Mean }\end{array}$ & $\begin{array}{l}\text { Standard } \\
\text { Deviation }\end{array}$ & Rank & Level \\
\hline 1 & I feel comfortable when I'm with my family & 4.73 & 0.69 & 1 & High \\
\hline 5 & I express my satisfaction in front of my family & 4.58 & 0.72 & 2 & High \\
\hline 9 & My relationship with my family is balanced & 4.55 & 0.68 & 3 & High \\
\hline 15 & I try to create an atmosphere of fun with my family & 4.48 & 0.85 & 4 & High \\
\hline 17 & My family appreciates my views & 4.30 & 1.15 & 5 & High \\
\hline 18 & I join my family in all social activities & 4.29 & 0.71 & 6 & High \\
\hline 21 & Confined my social relationships on my family & 4.29 & 1.16 & 6 & High \\
\hline 8 & I feel happy when I participate in the affairs of the house & 4.25 & 1.19 & 8 & High \\
\hline 10 & $\begin{array}{l}\text { My behavioral habits are doomed to the habits of my } \\
\text { family }\end{array}$ & 4.24 & 1.01 & 9 & High \\
\hline 13 & $\begin{array}{l}\text { Ashamed to answer the teacher's questions in front of } \\
\text { my colleagues }\end{array}$ & 4.23 & 1.02 & 10 & High \\
\hline 28 & I enjoy with my friends in their rituals & 4.22 & 0.96 & 11 & High \\
\hline 27 & I feel that my close friends are ignoring me & 4.17 & 1.00 & 12 & High \\
\hline 22 & It's difficult for others in school to accept to me & 4.11 & 1.29 & 13 & High \\
\hline 14 & $\begin{array}{l}\text { Being within a funny group of students takes me away } \\
\text { from my fears }\end{array}$ & 4.07 & 0.98 & 14 & High \\
\hline 2 & I accept the constantly communicating with new friends & 4.07 & 1.00 & 14 & High \\
\hline 23 & Be sure to participate in school activities & 4.03 & 1.08 & 16 & High \\
\hline 12 & Neglecting home works & 4.02 & 1.14 & 17 & High \\
\hline 16 & $\begin{array}{l}\text { I avoid being with a large group of my colleagues in the } \\
\text { school }\end{array}$ & 4.02 & 1.19 & 17 & High \\
\hline 6 & I miss the familiarity with my colleagues in the school & 4.01 & 1.06 & 19 & High \\
\hline 7 & I feel less patience with my colleagues in the school & 3.99 & 1.03 & 20 & High \\
\hline 24 & School helps me solve my problems & 3.97 & 0.96 & 21 & High \\
\hline 29 & Better to sit by myself in social events & 3.89 & 1.24 & 22 & High \\
\hline 26 & I am happy to create new social relationships & 3.78 & 0.96 & 23 & High \\
\hline 4 & I would love to get to know some important people & 3.60 & 1.09 & 24 & Medium \\
\hline 20 & I avoid social relationships as I could & 3.59 & 1.37 & 25 & Medium \\
\hline 25 & Participate in social events & 3.49 & 1.21 & 26 & Medium \\
\hline 11 & I'm afraid to enter a room a crowd of people & 3.47 & 0.92 & 27 & Medium \\
\hline
\end{tabular}




\begin{tabular}{|c|c|c|c|c|c|}
\hline 19 & $\begin{array}{l}\text { I find it difficult to talk with people I meet for the first } \\
\text { time }\end{array}$ & 2.79 & 1.31 & 28 & Medium \\
\hline \multirow[t]{2}{*}{3} & $\begin{array}{l}\text { I have a lot of embarrassment when I meet people for } \\
\text { the first time }\end{array}$ & 2.77 & 1.11 & 29 & Medium \\
\hline & Total & 4.00 & 0.64 & & High \\
\hline
\end{tabular}

Table 2 shows that the arithmetic means ranged between (2.77- 4.73), where paragraph (1) which states "I feel comfortable when I'm with my family" ranked first, with the arithmetic mean of (4.73), while paragraph (3), which states "I have a lot of embarrassment when I meet people for the first time" ranked last with the arithmetic mean of (2.77), and the average total arithmetic mean for the social adaptation as a whole was (4.00), and with a high level.

The results of the second question, which states: "What is the level of achievement motivation among secondary school students in the province of Jerash?"

To answer this question the arithmetic means and the standard deviations of the level of achievement motivation among secondary school students in the province of Jerash have been extracted, and illustrated in table 3 as follows:

Table 3. Arithmetic means and standard deviations of the level of achievement motivation among secondary school students in the province of Jerash in descending order according to the arithmetical means

\begin{tabular}{|c|c|c|c|c|c|}
\hline No. & Paragraph & $\begin{array}{l}\text { Arithmetic } \\
\text { Mean }\end{array}$ & $\begin{array}{l}\text { Standard } \\
\text { Deviation }\end{array}$ & Rank & Level \\
\hline 4 & I have a great desire to succeed & 4.62 & 0.66 & 1 & High \\
\hline 3 & $\begin{array}{l}\text { When complaining successfully any work, this will } \\
\text { encourage me to try more difficult tasks }\end{array}$ & 4.42 & 0.79 & 2 & High \\
\hline 11 & I keep repeating until I can master the work & 4.40 & 0.95 & 3 & High \\
\hline 9 & Withdrew from any difficult business quickly & 4.34 & 0.77 & 4 & High \\
\hline 12 & Complete my duties without any difficulty & 4.21 & 0.70 & 5 & High \\
\hline 5 & Do a lot of effort in my studies & 4.01 & 0.70 & 6 & High \\
\hline 18 & Competing with my colleagues & 3.87 & 0.84 & 7 & High \\
\hline 10 & $\begin{array}{l}\text { I have a lot of boredom shortly after the beginning of } \\
\text { any work }\end{array}$ & 3.87 & 1.05 & 8 & High \\
\hline 17 & Participate in additional activities & 3.86 & 0.93 & 9 & High \\
\hline 2 & Trying hard to be distinguished & 3.81 & 0.95 & 10 & High \\
\hline 16 & I have the determination to win in any competition & 3.68 & 1.17 & 11 & High \\
\hline 8 & I am a studiously person & 3.66 & 0.99 & 12 & Medium \\
\hline 7 & I am looking to outdo the others & 3.31 & 0.65 & 13 & Medium \\
\hline 15 & I challenge my ability to perform difficult tasks. & 3.25 & 1.37 & 14 & Medium \\
\hline 13 & $\begin{array}{l}\text { When I compare my performance with others, I find that } \\
\text { I need to do greater effort. }\end{array}$ & 3.18 & 1.19 & 15 & Medium \\
\hline 1 & Much homework causes me frustration. & 3.17 & 0.86 & 16 & Medium \\
\hline 14 & Prefer individual competitive games. & 2.54 & 1.12 & 17 & Medium \\
\hline \multirow[t]{2}{*}{6} & I feel upset whenever my level decline in school & 2.45 & 1.17 & 18 & Medium \\
\hline & Total & 3.70 & 0.46 & & High \\
\hline
\end{tabular}

Table 3 shows that the arithmetic means ranged between (2.54 - 4.62), where paragraph (4) which states "I have a great desire to succeed" ranked first, with the arithmetic mean of (4.62), while paragraph (6), which states "I feel upset whenever my level decline in school" ranked last with the arithmetic mean of (2.54), and the average of the total arithmetic means for the achievement motivation as a whole was (3.70), and with a high level.

The results of the third question, which states: Is there a statistically significant correlation at the level of ( $\alpha \leq$ 0.05 ) between the level of social adaptation and achievement motivation among secondary school students in the province of Jerash? 
To answer this question Pearson correlation coefficient between the level of social adaptation and achievement motivation among secondary school students in the province of Jerash has been extracted, as illustrated in table (1.4) bellow:

Table 4. Pearson correlation coefficient between the level of social adaptation and achievement motivation among secondary school students in the province of Jerash

\begin{tabular}{ll}
\hline Correlation Coefficient & Significance \\
\hline 0.44 & 0.01 \\
\hline
\end{tabular}

Table 4 shows that the value of the correlation coefficient between the social adaptation and the achievement motivation among these secondary school students was (0.44), which is functional at the level of $(\alpha=0.05)$, so there is a statistically significant correlation between social adaptation and achievement motivation among the secondary school students in the province of Jerash.

\section{Results Discussion}

7.1 Results Discuss of the First Question Which States: "What is the Level of Social Adaptation among the Secondary School Students in the Province of Jerash?"

Results in table (1.2) showed that the level of social adaptation for these students was high, this is related to the fact that these students at the age of secondary levels are more qualified to do various social activities, and to became more social effective participants in their societies with their own opinion and their own entity, and with a great ability to develop an active responsible personality that incorporates them in their communities, which of course will rise their level of social adaptation.

The result also indicated that the level of social adaptation of the individual is greatly affected by social interaction with the external environment, and the student at this stage starts out his social interactions to become responsible for carrying out the social duties as becoming a social responsible member in the community, which of course will contribute significantly in his social adaptation.

7.2 Results Discuss of the Second Question Which States: "What is the Level of Achievement Motivation among the Secondary School Students in the Province of Jerash?"

results in the table (1.3) showed that the level of achievement motivation among the secondary school students in the province of Jerash came high, indicating that the level of achievement motivation among these students commensurate with the magnitude of challenges they are facing and with their level of thinking, as they are in front of an important step in their lives; which is a transition to a new phase of life that will require high efforts to achieve great objectives, and this in turn contributes significantly in rising the level of achievement motivation among these students.

Secondary school stage in Jordan is an important stage in the life of the students, it is the stage that rules their fate, as the acceptance of the student at the university, and choosing the specialization they want depend on the rates of this stage, which calls for more seriousness and diligence.

In addition to that, achievement motivation influence the determination of performance and productivity levels in various fields and activities, including the educational field, and the academic achievement motivation refers to the force that rules the student's behavior linked with his academic achievement.

7.3 Results Discuss of the Third Question Which States: "Is There a Statistically Significant Correlation at the Level of $(\alpha \leqslant 0.05)$ between the Level Of Social Adaptation and Achievement Motivation among Secondary School Students in the Province of Jerash?"

Results in table (1.4) showed that there is a statistically significant correlation in the relationship between social adaptation and achievement motivation among secondary school students in the province of Jerash.

This result is supported by the interpretation which declares that social adaptation of any individual leads to a balance in the relationship with his environment, his peers and his school, which of course will increase the his achievement motivation, and will help him exploiting his energies and abilities to the possible fullest extent.

This is due to the fact that the socially adaptive individual with the surrounding environment, family and school satisfies his basic needs, in which he can raise the levels of his ambitions, which of course will assist achieving 
higher goals of social and academic targets, and the idea of development and evolution become motivated to progress, and this shows that the socially adaptive individual is more motivated to achievement and vice versa.

Achievement motivation is also the driving force for guiding the student's behavior towards accepting the challenge in all situations that require excellence, and to exert much more serious attempts to achieve success, thereby this shows that the social adaptation of the individual with his environment is influenced by the level of his achievement motivation.

The adaptive individual reaches a stage the conforms and fits his behaviors and actions with his surrounding social environment, and this will achieve a balanced positive social relationships with the social milieu around him, which of course will affects positively his different aspects of life; especially his motives towards the achievement, since the motivations and needs of achievement is one of the highest social needs that the individual seeks.

It could be argued that achievement motivations is strongly linked with the behavior of the individual, and that gives it the great importance in psychology, in trying to explain more of the human behavior in light of the achievement motivation, and that the performance of the individual depends on the quality of his motivations.

\section{Recommendations}

In light of the study results the researcher recommends the following:

- Strengthen cooperation between schools and various social institutions to maintain high level of social adaptation.

- Motivate students to maintain acceptable levels of achievement motivation.

- Conduct further studies in analyzing more variables related to social adaptation and achievement motivation in other societies, and more samples.

\section{References}

Abdullah, Muhammad Qasim. (2001). Introduction to mental health. Dar Alfker, Amman, Jordan.

Adeymo, David. (2005). The Buffering Effect of Emotional Intelligence on the Adjustment of Secondary School Students in Transition. Electronic Journal of Research in Education Psychology, 3(2), 79-90.

Ahmed, Mohammed Mustafa. (1996). Adaptation and school problems. Dar Al-Marrfa, Alexandria, Egypt.

Anani, Hanan. (2000). Mental health. Dar Alfker Amman, Jordan.

Areepattamanil, S., \& Freeman, J. (2008). Academic Achievement, Academic Self-Concept and Learning Motivation of Immigrate Adolescents in the Greater Toronto Area Secondary Schools. Journal of Advanced Academics, 19(4), 700-743.

Cerezo, Maria, \& Casanova, Pedro (2004). Gender Differences in Academic and Learning Motivation of Secondary School Students. Electronic Journal of Research in Educational Psychology, 2(7), 97-112.

Chex, X., Wang, L., \& Cao, R. (2011). Shyness, Sensitivity and Unsociability in Rural Chinese School Students: Relations with Social, School and Psychological Adjustment. Child Development Journal, 82(5), 1531-1543. http://dx.doi.org/10.1111/j.1467-8624.2011.01616.x

Mayahi, Jaafar Kadhim. (2010). Motivated behavior. Amman: Dar Al-Konooz of, Amman, Jordan.

Mousa, Rashad, \& El-Desoki, Madiha. (2000). Problems and mental health. Al- Farouk Modern Publishing, Cairo, Egypt.

Taylor, M. (1998). The Relationship between the Social and Academic Adaptation for Foreign Students in the Light of Some Variables. Unpublished Doctorial Thesis. DIA, 58(21), 21954-A.

Teang, Alexander, Lau, Shung, \& Nie, Touyan. (2011). Primary and Secondary Students Motivation in Learning English: Gender and Grade Differences. Contemporary Education Psychology Journal, 36(3), 246-256. http://dx.doi.org/10.1016/j.cedpsych.2011.03.001

Wilson, B. (1994). Problems of University Adjustment Experienced by Undergraduates in a Developing Country. Higher Education Journal, 13, 1-22. http://dx.doi.org/10.1007/BF00136528

\section{Copyrights}

Copyright for this article is retained by the author(s), with first publication rights granted to the journal.

This is an open-access article distributed under the terms and conditions of the Creative Commons Attribution license (http://creativecommons.org/licenses/by/3.0/). 